\title{
Avatares y cajas de herramientas: Identidad digital y sentido del aprendizaje en adolescentes de secundaria ${ }^{1}$
}

\author{
Avatars and Toolboxes: Digital Identity and Sense of Learning in High School Adolescents ${ }^{2}$ \\ Avatares e caixas de ferramentas: identidade digital e senso de aprendizagem em \\ adolescentes do ensino médio ${ }^{3}$
}

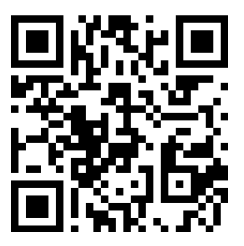

\footnotetext{
${ }^{1}$ Este reporte forma parte de una investigación que se realizó entre 2017-2018 como parte del proyecto "Aprender con sentido. Estrategias, instrumentos y prácticas de personalización del aprendizaje escolar" dirigido por César Coll (Universidad de Barcelona), auspiciado por el Instituto de Tecnologías para el Aprendizaje (INTEA) y la Fundación SM. El proyecto también recibió apoyo de DGAPA-UNAM a través del proyecto PAPIME PE300217. La coordinadora en la sede México es la primera autora de este artículo.

${ }^{2}$ This report is part of a research project conducted between 2017-2018 as part of the project "Learning with Sense: Strategies, Instruments and Practices for Personalizing School Learning," led by César Coll (University of Barcelona), sponsored by the Institute of Learning Technologies (INTEA) and the SM Foundation. The project also received support from DGAPA-UNAM through the PAPIME PE300217 project. The coordinator in Mexico City is the first author of this article.

${ }^{3}$ Este informe é parte de uma pesquisa realizada entre 2017-2018, como parte do projeto "Aprender com sentido. Estratégias, instrumentos e práticas de personalização do aprendizado escolar" dirigido por César Coll (Universidade de Barcelona), auspiciado pelo Instituto de Tecnologias para a Aprendizagem (INTEA) e a Fundação SM. O projeto também recebeu apoio de DGAPA-UNAM através do projeto PAPIME PE300217. A coordenadora da sede do México é a primeira autora desse artigo.
} 
doi: http://doi.org/10.15359/ree.24-1.1

URL: http://www.una.ac.cr/educare

CORREO: educare@una.cr

Resumen: Se presenta un estudio cualitativo de casos con un grupo de adolescentes de secundaria en situación de vulnerabilidad académica y riesgo social, a quienes se les pidió desarrollar dos tareas con la finalidad de explorar su identidad de aprendices en contextos formales e informales. Mediante aplicaciones digitales libres, realizaron un avatar (dibujo identitario) y una caja de herramientas (artefactos culturales que emplean para aprender), así como una narración que explica su sentido. Los sujetos participantes no se autodefinieron como personas adolescentes problemáticas ni con déficits para aprender; pero manifestaron falta de motivación y disposición por el aprendizaje escolar, debido a los contenidos curriculares, las formas de enseñanza y la operación del reglamento escolar. Los aprendizajes que generan más sentido y símbolos de identidad ocurren en relación con la cultura mediática juvenil, así como con prácticas socioculturales de comunicación y recreación en el ciberespacio. No reportan la vinculación entre aprendizaje formal e informal ni personalización de los aprendizajes escolares, lo que dificulta la construcción del sentido de estos últimos.

Palabras claves: Educación secundaria; identidad de la persona aprendiz; sentido del aprendizaje; narrativa autorreferencial; dibujo identitario digital.

Abstract: In this qualitative case study, a group of secondary school students, in a situation of academic vulnerability and social risk, were asked to develop two tasks to explore their identity as learners. The teenagers made digital infographics with an avatar (identity drawing) and a toolbox (cultural artifacts they use to learn), as well as a narrative that explains their meaning. The participants did not define themselves adolescents as problematic or with learning deficits, but they expressed a lack of motivation and inclination for school learning due to the curricular contents, the forms of teaching, and the management of school regulations. The types of learning that generate more sense and create identity symbols occur in relation to the youth media culture, as well in their communication and recreation practices in cyberspace. They do not report the link between formal and informal learning nor personalization of school learning activities, which hinders the construction of sense and meaning in school settings.

Keywords: Secondary education; identity of the apprentice; sense of learning; self referential narrative; digital identity drawing.

Resumo: Um estudo de caso qualitativo é apresentado a um grupo de adolescentes do ensino médio em situação de vulnerabilidade acadêmica e risco social, os quais foram solicitados a desenvolver duas tarefas para explorar sua identidade como aprendiz. Por meio de aplicativos digitais gratuitos, eles criaram um avatar (desenho de identidade) e uma caixa de ferramentas (artefatos culturais que usam para aprender), além de uma narrativa que explica seu significado. Os participantes não se definiram como adolescentes problemáticos ou com déficits para aprender; mas expressaram falta de motivação e disposição para a aprendizagem escolar, devido aos conteúdos curriculares, às formas de ensino e ao funcionamento dos regulamentos escolares. Os aprendizados que geram mais sentido e símbolo de identidade ocorrem na relação com a cultura da mídia jovem, bem como às práticas socioculturais de comunicação e recreação no ciberespaço. Eles não reconhecem a ligação entre a aprendizagem formal ou informal ou a personalização da aprendizagem escolar, o que dificulta a construção de significados nas actividades escolares.

Palavras chave: Ensino secundário; identidade do aprendiz; sentido de aprendizagem; narrativa autorreferencial; desenho de identidade digital. 


\section{Introducción}

García (2008) afirma que la construcción de la identidad es un proceso paradójico que transcurre en la interacción dialéctica entre unicidad (lo que nos hace existir como ser único) y unidad (la pertenencia a un grupo con el que compartimos valores y características comunes). Debido a lo anterior, la pregunta identitaria clásica: ¿quién soy yo?, solo tendrá sentido acompañada de otras dos: ¿cómo se sitúo en el mundo?, ¿cómo son mis relaciones con otros sujetos?, dado que la génesis de toda identidad reside en la relación interactiva con otro u otros individuos. Poseemos identidades múltiples, no estáticas, vinculadas a nuestros grupos de pertenencia, a veces complementarias, pero que también llegan a entrar en contradicción. A su vez, Jerome Bruner postula que las personas tenemos identidad porque somos capaces de narrar historias sobre nosotras mismas. Es decir, la identidad se plasma mediante la autodefinición e interpretación que hace una persona de sí misma, recuperando y resignificando sus vivencias. La forma de autodefinirse es mediante una narrativa que aporta sentido y unidad a dichas vivencias (Bruner, 2004, 2012, 2013). Así, no hay otra manera de describir el tiempo vivido que a través de una narrativa autobiográfica o historia de vida, nos conduce a revisitar continuamente la propia identidad. Es decir, el pensamiento narrativo es una capacidad tanto individual como universal, y es la operación fundamental para la construcción de sentido que posee la mente que conduce a la construcción de mundos posibles, dada la posibilidad de desprenderse de lo real, del aquí y el ahora. Por otra parte, la narrativa de los sucesos vitales da cuenta, por un lado, del devenir del autor o autora, pero también de la cultura a la que pertenece, del tiempo que le toca vivir (Bruner, 2012).

La identidad no es una construcción personal en solitario: únicamente puede entenderse atendiendo su doble génesis, histórica y biográfica, y cobra significado gracias a la participación de los seres humanos en la cultura (Ricoeur, 1995). Por otro lado, en el proceso biográfico ocurre una transacción subjetiva, con relación con la identidad deseada o la proyectada y la heredada generacionalmente; de tal manera que para Kossoy (2009, p. 2) "las biografías tienen sentido en el marco de las estructuras y culturas, a pesar de que impliquen caminos particulares de construcción individual". Para esta investigadora, cuando se intenta un acercamiento a develar la identidad de jóvenes, hay que evitar una visión fragmentaria que les encasilla en un rol único (por ejemplo, de estudiante) e intentar comprender la interacción de distintas experiencias en torno a diversas instituciones, para recuperar las transacciones subjetivas que realizan y se vinculan con la re-co-construcción de sus identidades. También será de gran interés entender las tensiones existentes entre las identidades que se les imponen o atribuyen con las que ellos y ellas reivindican.

Las instituciones suelen atribuir determinadas identidades a ciertos grupos o colectivos sociales, que pueden o no identificarse con estas (Dubar, 2002). Por ejemplo, cuando se estereotipa a adolescentes de los sectores sociales marginales y se afirma que son delincuentes o pertenecen a 
doi: http://doi.org/10.15359/ree.24-1.1

URL: http://www.una.ac.cr/educare

CORREO: educare@una.cr

pandillas, o cuando se dice que la juventud actual son ninis porque ni estudian ni trabajan porque no quieren hacerlo. En congruencia con lo anterior, hay que reconocer que no podemos hablar de forma genérica ni universalista de los grupos de adolescentes, tampoco de adolescentes de México, o de adolescentes de secundarias públicas, sin reconocer la diversidad al interior de estos colectivos. Cuando se habla de adolescentes o de jóvenes, no se alude a etapas o estadios universales del ciclo de vida, sino a construcciones sociohistóricas y situadas en contexto:

De hecho, no hay "juventud" sino juventudes. Se trata de una condición históricamente construida y determinada, cuya caracterización depende de diferentes variables, siendo las más notorias la diferenciación social, cultural, el género y la generación. (Margulis, 2001, p. 42)

La identidad, en cuanto expresión narrada de la propia vida, permite entender cómo nos vamos transformando (vamos siendo) a través de interacciones, actos, palabras, expectativas, proyectos y acompañamiento de otros seres humanos. Así, la construcción de la identidad, tanto en la esfera de lo intrasubjetivo como en la intersubjetiva, se caracteriza por procesos de índole emocional e interpretativa, pero a la par, de reflexión y razones. Son factores que se entrecruzan en la construcción de una identidad que se enfoca en un llegar a ser, como proyecto de vida (Ramírez, 2011). Por ello, lo más interesante del trabajo con narrativas identitarias en la educación es poder analizar la interrelación de las experiencias personales con determinados modelos sociales, entre la historia personal y el proyecto de sí con las determinaciones sociohistóricas de la época que nos toca vivir.

\section{Los fondos de identidad y su exploración a través de dispositivos biográfico-narrativos}

En este trabajo asumimos una perspectiva sociocultural, donde se asume que los fondos de identidad humanos están conformados por "artefactos, tecnologías o recursos, históricamente acumulados, culturalmente desarrollados, socialmente distribuidos y transmitidos, esenciales para la autodefinición, autoexpresión y autocomprensión de las personas" (Esteban-Guitart y Saubich, 2013, p. 201). Identificar tales fondos de identidad permite arribar a una perspectiva ecológico-sistémica de la construcción identitaria y mucho más analítica, mientras que, en el plano educativo, conduce a plantear situaciones educativas más ajustadas a la diversidad del alumnado (Esteban-Guitart, 2012). Al respecto, Esteban-Guitart y Saubich (2013) postulan las siguientes categorías de fondos de identidad:

- Fondos geográficos de identidad, que consisten en aquellos territorios con los que las personas muestran una importante vinculación e identificación.

- Fondos sociales de identidad, consisten en las personas y relaciones más significativas, las redes sociales con las que contamos. 
- Fondos culturales de identidad: instrumentos, artefactos físicos o simbólicos para autoexpresarse o autodefinirse.

- Prácticas de identidad o fondos prácticos de identidad, que consisten en actividades que uno realiza y que suelen ser las más significativas.

- Fondos institucionales de identidad, que son mecanismos de orden social y cooperación que normalizan la conducta de las personas.

Los fondos de identidad se pueden explorar a través de una serie de dispositivos derivados de la investigación cualitativa de corte etnográfico y psicosocial, como es el caso de la multimetodología autobiográfica extendida (MAE). En estudios previos se ha encontrado que la construcción de narrativas personales y representaciones identitarias icónicas y multimedia, que son ejemplos del tipo de dispositivos $\mathrm{MAE}$, constituyen un medio idóneo para la exploración y auto-reflexión de la identidad en los planos intra e intersubjetivo, particularmente en los aprendices jóvenes, a la par que conducen a entender la identidad que han construido en el mundo de la virtualidad (Díaz Barriga, López y Vázquez-Negrete, 2018; Díaz Barriga, VázquezNegrete y Díaz-David, 2019; Poole, 2017a, 2017b).

El acercamiento a la identidad narrativa de adolescentes, en su cualidad de aprendices en entornos escolares y no escolares, permite comprender cuáles son las prácticas que les generan más sentido (motivación por aprender, disposición e implicación, emociones positivas ligadas a las actividades de aprendizaje). Al respecto, Coll (2013) habla de una creciente pérdida del sentido de la educación formal en estudiantes, que ha sido identificada como uno de los factores responsables del fracaso y del abandono de los estudios. En contraposición, el aprendizaje informal, particularmente el que se encuentra mediado por tecnologías digitales y el que proviene de redes sociales y de entornos mediáticos orientados a la recreación, la convivencia o la producción de contenidos no académicos, ha tomado un importante auge entre la población juvenil. Cassany y Hernández (2012) ponen en manifiesto que las prácticas académicas escolarizadas no se corresponden ni complementan con las prácticas vernáculas en el mundo digital que realizan los grupos de jóvenes. Con frecuencia, la institución escolar permanece ajena a los nuevos alfabetismos, no recupera las prácticas de aprendizaje cotidianas de niños, niñas y jóvenes, sobre todo las que les generan el mayor sentido, e insiste en tareas escolares desvinculadas de sus intereses vitales.

El conocimiento de los fondos de identidad de distintos colectivos juveniles es relevante como objeto de investigación en cuanto permite conocer los procesos e influencias subyacentes al proceso de construcción del yo en los planos inter e intrapersonal, en el contexto de la dinámica sociohistórica actual. En el terreno educativo, su relevancia reside en poder fortalecer la continuidad entre lo que se aprende en la escuela con lo que se aprende fuera de ella, a través de identificar los escenarios, prácticas sociales y artefactos culturales que generan una 
doi: http://doi.org/10.15359/ree.24-1.1

URL: http://www.una.ac.cr/educare

CORREO: educare@una.cr

mayor disposición por aprender y permiten aprendizajes significativos en el marco de los intereses y necesidades estudiantiles. En el caso del estudiantado, la exploración de los fondos de identidad de aprendiz puede convertirse en un dispositivo pedagógico que, mediante de la narrativa autorreferencial y la iconografía personal, apoyan la comprensión de sí mismo o de sí misma, y la reflexión sobre la propia trayectoria de aprendizaje.

\section{Método}

\section{Planteamiento del problema}

Ante lo antes expuesto, nuestro objeto de estudio reside en comprender, desde la propia voz de adolescentes y desde sus narrativas identitarias, cuáles son aquellos fondos de identidad que les permiten autodefinirse; los artefactos culturales y las prácticas sociales que les generan mayor sentido al aprender en diversos contextos; los símbolos con los que se identifican o las personas/personajes en los que se proyectan.

Para tal fin se adaptaron algunos dispositivos de la MAE que permiten proyectar y simbolizar los fondos de identidad de adolescentes, a través de una serie de tareas narrativas en formato textual e icónico. En el caso que aquí nos ocupa, describiremos lo encontrado con la construcción de avatares (dibujo identitario) y cajas de herramientas (artefactos culturales que median sus aprendizajes). El uso de estos dispositivos, a la vez que permite la indagación cualitativa de la identidad narrativa, tienen una función de dispositivos pedagógicos (Sanjurjo, 2009), porque ayudan a adolescentes a tomar conciencia y reflexionar sobre sus propias necesidades e intereses, vincular sus aprendizajes formales e informales, así como a incorporar nuevas prácticas y tecnologías digitales.

\section{Preguntas de investigación}

- ¿Cómo se representan y autodefinen un grupo de estudiantes de México de secundaria pública cuando elaboran un dibujo identitario (avatar) e identifican sus artefactos culturales (caja de herramientas)?

- ¿Qué tipo de fondos de identidad aparecen en sus representaciones identitarias y qué significado le atribuyen sus autores y autoras?

- ¿En qué medida los fondos de identidad de los grupos de adolescentes en el escenario de aprendizaje formal (escuela) son o no coincidentes con sus aprendizajes mediáticos y en la virtualidad? 


\section{Tipo de estudio}

Se condujo una investigación cualitativa, de tipo biográfico-narrativo. De acuerdo con Amar-Rodríguez (2016), la investigación narrativa, dada su cualidad interpretativa, busca descubrir lo que dice y siente la persona participante; no es un estudio externo del sujeto, sino la posibilidad de desvelar su subjetividad y darle voz. Se trata asimismo de un estudio de casos múltiple, de acuerdo con Stake (2005), donde se conjuntan distintas perspectivas para la formulación de situaciones de vida y para la comprensión del entorno de un grupo humano determinado.

Puesto que esta investigación no es un estudio sobre el estudiantado, sino con este y desde este, la dinámica de trabajo se condujo en torno a un taller lúdico-reflexivo (TLR), que junto con la metodología autobiográfica extendida (MAE) conforme a Peña-Cuanda y Esteban-Guitart (2013), constituyeron las dos estrategias metodológicas empleadas en la exploración de los fondos de identidad y el sentido del aprendizaje en contextos formales e informales.

\section{Participantes y contexto educativo}

Participaron estudiantes de ambos sexos con edad promedio de 15 años, de la Secundaria Técnica 101, ubicada en Iztapalapa, Ciudad de México, en una zona de alto índice delictivo con problemas de acceso a servicios públicos y narcomenudeo. Los estudiantes y las estudiantes cursaban $3^{\circ}$ grado y estaban integrados en un grupo de 33 estudiantes conformado exprofeso por las autoridades de la escuela, debido a que tenían varias asignaturas reprobadas y en varios casos tenían reiterados reportes de mal comportamiento o habían sido sujetos de expulsión temporal de la escuela; estaban en riesgo de no concluir el tercer grado y, por ende, no obtener el certificado de educación secundaria. Por tanto, no se trata de una muestra aleatorizada ni representativa, sino de tipo intencional.

En la escuela se les conocía como sujetos menores infractores que era la etiqueta que muestra la identidad atribuida socialmente a este grupo de adolescentes. El cuerpo directivo del plantel conformó este grupo y solicitó a nuestro equipo de investigación impartir un taller de regularización para superar el problema de rezago y reprobación, a fin de concluir el tercer grado y obtener el certificado escolar.

Este grupo en particular reviste un especial interés en el estudio del sentido del aprendizaje, pues como apunta Sinisi (2010, p. 11), hay que repensar los complejos procesos que atraviesan la experiencia escolar de estos chicos y chicas "que ven cercenado su derecho a acceder/permanecer en la escuela común por ser portadores de 'patologías cognitivas,',mala conducta', síndrome [de atención dispersa], discapacidades, o por ser pobres", dada la identidad que se les atribuye, suelen vivir estigmatización y segregación. 
doi: http://doi.org/10.15359/ree.24-1.1

URL: http://www.una.ac.cr/educare

CORREO: educare@una.cr

Desde nuestra perspectiva, se trata de jóvenes en situación de vulnerabilidad académica y riesgo social, pero con capacidades y un potencial de aprendizaje que expresan en otros escenarios y áreas de la vida, donde se les genera más sentido que en la institución escolar. A partir de dicho potencial, muestra de educabilidad, se puede replantear su trayecto escolar y fortalecer el sentido del aprendizaje. Se ha encontrado que vincular aprendizajes formales e informales, sobre todo con tecnologías digitales que les son de interés en la vida cotidiana, fortalece la continuidad educativa y conduce a replantear trayectorias personales de aprendizaje (Subero, 2018).

Se trabajó en el aula de cómputo y en un aula regular todos los viernes durante un semestre escolar. Se conducía trabajo individual, colaborativo y plenarias de discusión. En este reporte se incluyen los resultados de 9 casos, 7 alumnos de sexo masculino y 2 de sexo femenino, en lo relativo a dos de las tareas realizadas al inicio del taller: la construcción de un avatary una caja de herramientas.

\section{Procedimiento}

\section{Diseño del avatar}

El avatar es una representación gráfica de sí que se emplea en internet y diversas tecnologías virtuales para identificar a una persona usuaria en dicho escenario virtual. En algunos casos se emplean fotografías reales (por ejemplo, en las plataformas educativas), pero en el caso de jóvenes y en el contexto de la recreación o la educación informal, es más común seleccionar o construir auto-representaciones con personajes bi o tridimensionales que expresan símbolos de identidad propios. Esto permite recrear de manera idealizada el físico del autor o autora, modificarlo, adoptar los rasgos de algún personaje real o de ficción, e incluso cambiar el nombre o el género o transmutarse en un héroe o heroína mediático, en un animal mítico, en un objeto o ente abstracto. Es decir, el avatar puede ser una suerte de imagen del yo idealizado o aspiracional, que promueve procesos de catarsis e integración y puede movilizar emociones, debido a que conduce a andamiar el progreso a través de una zona de desarrollo próximo de la identidad del individuo (Poole, 2017a). Los sujetos participantes emplearon la aplicación Face Q o similar, que es una app gratuita descargable o para trabajar en línea, que permite crear un avatar con base en una serie de plantillas para lograr la máxima personalización posible. Cabe mencionar que las aplicaciones empleadas en el estudio se eligieron por ser gratuitas y sencillas de manejar, accesibles en los teléfonos celulares y porque se prestaban a ilustrar las tareas identitarias requeridas.

\section{Diseño de la caja de herramientas}

Con relación a la tarea de la caja de herramientas, la idea es que se plasmaran al menos 5 artefactos culturales que resultaran más relevantes para los adolescentes y las adolescentes y 
que fueran indispensables en su día a día, que les apoyaran a aprender en distintos escenarios. La relevancia de esta tarea reside en la importancia de la mediación cultural, dado que la perspectiva sociohistórica "inspirada en Vygotsky [plantea] que el aprendizaje se encuentra mediado por herramientas físicas o técnicas y signos o herramientas semióticas (también denominadas instrumentos psicológicos, v. Kozulin, 2000)" (Díaz Barriga, 2005, p. 7). De acuerdo con Kozulin (2000) y con base en las tesis vigotskianas, se pueden considerar tres categorías de instrumentos mediadores: los instrumentos u objetos materiales, los de índole psicológica y los propios seres humanos. En el caso del alumnado que participó en esta investigación, integraron el avatar y la caja de herramientas en una infografía en la aplicación gratuita Genially, donde colocaron ilustraciones alusivas a su caja de herramientas. Podían ilustrar con las imágenes que desearan las herramientas que emplean tanto en la escuela como fuera de ella y tenían que narrar sus producciones. Se les indicó que tenían amplia libertad para usar el nombre que desearan y para caracterizarse como eran o les gustaría ser, pero tenían que narrar sus producciones para entender el porqué de sus representaciones. Asimismo, conforme al avance en el taller, se realizaban plenarias para la presentación y reflexión sobre las producciones. La validación de discursos y representaciones, mediante la ampliación o reiteración de explicaciones, se dio en las plenarias de discusión de producciones, donde exponían sus trabajos y se comentaban grupalmente. La segunda autora del estudio, que fungía como docente-tutora del grupo, planteaba interrogantes para arribar a un sentido más profundo de las producciones y corroboraba con los sujetos participantes sus explicaciones.

Para proceder al análisis, se buscó evidencia para caracterizar los distintos fondos de identidad plasmados en avatares y cajas de herramientas, así como de otros elementos que hubieran sido incluidos; se buscó identificar aquellos referidos a la vida escolar, la cotidianidad y el ciberespacio, dado que desde un inicio fueron los territorios de aprendizaje definidos por el grupo de adolescentes como los más relevantes.

\section{Resultados}

\section{Tipo de avatares}

Se tomó en cuenta la clasificación que hace Poole (2017a) del tipo de avatares generados. En este grupo, se generaron principalmente avatares epónimos (7 casos), en los que se buscan representar a sí mismos o mismas, su nombre y rasgos de identidad físicos, aunque idealizados o representados con símbolos de identidad aspiracionales, relacionados con influencias de la cultura popular mediática, que resultó de gran interés para este grupo. Dos varones crearon avatares sinónimos, en los cuales no cambiaron sus nombres reales Inti y Eddie, pero sí cambiaron su representación física real por una lo más similar a sus héroes de ficción y personajes de cómics, como es el caso del hombre verde Hulk o Mr. Satan de Dragon Ball Z (Ver Figura 1). 
doi: http://doi.org/10.15359/ree.24-1.1

URL: http://www.una.ac.cr/educare

CORREO: educare@una.cr

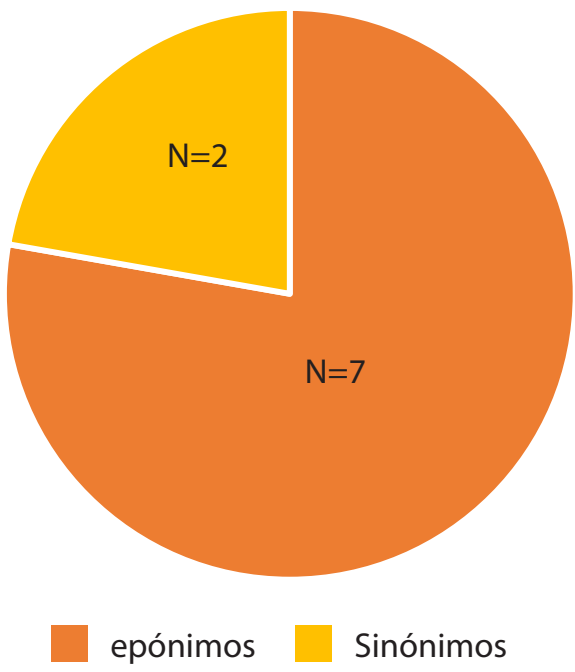

Figura 1: Avatares creados por adolescentes de secundaria (clasificación basada en Poole, 2017a). Nota: Elaboración propia.

\section{Entre los útiles escolares y el teléfono celular}

En las infografías de este grupo de adolescentes no se plasma como rasgo principal la identidad digital cuando hacen referencia a los aprendizajes escolares, y los artefactos que emplean se refieren a instrumentos de escritura, útiles escolares, mobiliario, zapatos tenis y uniforme escolar principalmente, que es lo que da sentido a las prácticas socioculturales que predominan en la escuela y lo que genera identidad en dicho escenario. En su plantel no hay un uso recurrente ni habitual de las tecnologías digitales con fines educativos, no tienen acceso a internet en las aulas o espacios escolares, y salvo con restricciones, solo en la sala de cómputo. El uso de internet con fines de aprendizaje escolar es para las tareas que realizan en casa, sobre todo búsqueda información que sus docentes llaman investigación. Esta información pudo corroborarse tanto en las producciones de nuestro grupo participante, como a través de las discusiones en el taller y mediante observaciones de las investigadoras en el plantel, durante el semestre que duró la experiencia educativa.

En la Figura 2 se ilustra el número de menciones que realizan el estudiantado de sus cinco artefactos más importantes. Cabe hacer notar que cuando hacen referencia a los artefactos de aprendizaje en el contexto escolar, lo que más se menciona son los instrumentos de escritura (plumas, lápices, colores, etc.) con 12 menciones, mientras que solo 3 chicos incluyeron en su caja de herramientas los libros y únicamente dos hablaron de su docente. Las explicaciones hacen 
referencia, sobre todo al uso funcional de los objetos, por ejemplo, las plumas (bolígrafos) o los lápices son para escribir o dibujar, y en menor medida se destaca su función como instrumento de mediación para el proceso de aprendizaje: para expresarme, para tomar mis apuntes, o dicen que el lápiz es importante porque puedes borrar lo que te equivocaste, o te permite hacer borradores.

Sin embargo, cuando se ilustran con imágenes los artefactos culturales que dan más sentido a su identidad, los que consideran más importantes y a los que no están dispuestos a renunciar, es cuando aparecen las herramientas del mundo digital, destacando el teléfono celular como el más importante. En la escuela no tienen permitido el teléfono celular, pero lo llevan a escondidas y cuando pueden lo utilizan, principalmente se ponen audífonos y escuchan música (una chica dijo que era para cuando se aburre en las clases, lo que es frecuente). En las ilustraciones que colocaron en sus infografías, en el contexto de aprendizaje y recreación fuera de la escuela, aparecen artefactos como teléfono celular, laptop, memoria USB, video juegos y consolas; emblemas deportivos, balones, gorras y ropa juvenil. Estos, en su mayoría, no son objetos permitidos en la escuela. Cuando mencionan a súper héroes y jugadores de futbol, sobre todo en el caso de los varones, son personajes en los que depositan símbolos de identidad aspiracionales, en los que proyectan rasgos con los que se identifican. En las producciones y en las plenarias, se hizo mención reiterada al gusto por la música y los grupos juveniles coreanos, por la vestimenta y arreglo personal que muestran, así como por determinados deportistas.

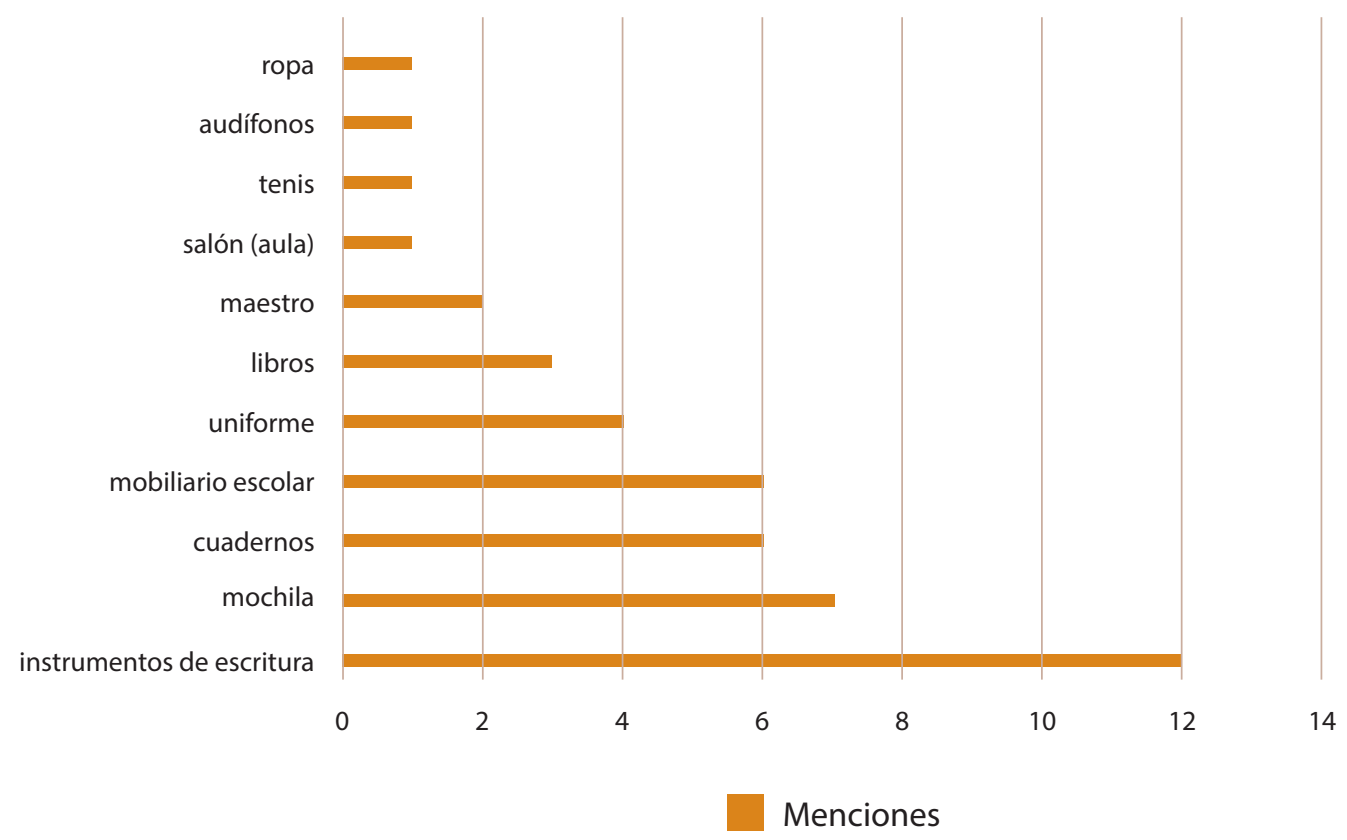

Figura 2: Caja de herramientas del aprendiz en el contexto escolar. Nota: Elaboración propia con datos de la investigación. 
doi: http://doi.org/10.15359/ree.24-1.1

URL: http://www.una.ac.cr/educare

CORREO: educare@una.cr

\section{Dos adolescentes ilustran las identidades escolar y digital}

En las Figuras 3 y 4 se ilustran dos ejemplos de avatares y cajas de herramientas, el primero desarrollado por una chica y el segundo por un chico.

En el caso de América ${ }^{4}$ se ilustra un avatar epónimo (trata de dibujarse lo más similar a su apariencia real) y los artefactos que dan sentido a la vivencia en la escuela, mientras que lo que da más sentido a su experiencia de aprendizaje fuera de la escuela se relaciona con las habilidades para dibujar animé que ha ido perfeccionando esta adolescente en su incursión en la red, a través de tutoriales, practicando por su cuenta o viendo cortos animados; su aspiración es dedicarse al dibujo artístico aunque no está segura de poder lograrlo, si su padre y madre no están de acuerdo. Es una joven reconocida en la escuela por su inteligencia y capacidad para el dibujo, pero su rendimiento escolar ha decaído notablemente, no se encuentra motivada por los estudios, se aísla en clases y considera no ser aceptada ni tener amigos.

En el segundo caso, Eddie creó un avatar sinónimo (él se convierte en un hombre verde como Hulk) y las imágenes que incluye se relacionan con el personaje de ficción con el que se identifica, pero lo que explica como artefactos culturales propios de su identidad escolar tiene que ver con instrumentos de escritura (lápiz), para portar útiles (mochila), mobiliario escolar (banca para estar cómodo). Llama la atención que el uniforme escolar es importante (si no llegan a la escuela portando el uniforme completo, limpio y en buen estado se les niega el acceso a clases), y es uno de los dos chicos que mencionaron al maestro para que me enseñe. Sus intereses y aprendizajes por iniciativa propia se ubican en el mundo de los videojuegos y los personajes de ficción.

Al igual que el resto del grupo, este par de estudiantes otorga la mayor importancia, como símbolos de identidad y de aprendizajes que les motivan, a aquellos relacionados con las prácticas socioculturales en las que se implican en relación con la cultura adolescente y las tecnologías digitales enfocadas al uso del tiempo libre. En ambos casos, los aprendizajes vinculados con ellas son en los que hay iniciativa propia, una dedicación considerable de tiempo y en los que buscan información por cuenta propia, comparten con sus pares y se autoimponen metas o retos. Se trata de aprendizajes autoiniciados, con un gran sentido personal y que han ido perfeccionando por su cuenta, con los que sienten confianza de sus habilidades.

Cabe mencionar que nuestro grupo de participantes indicó que no conocían las aplicaciones empleadas y que con anterioridad no habían realizado tareas de exploración de su propia identidad como las de esta investigación.

\footnotetext{
${ }^{4}$ Se incluyen los nombres que los adolescentes y las adolescentes dieron a sus avatares, en el entendido de que es un nombre de pila que no permite identificar datos personales que puedan generar alguna afectación o situación de riesgo. Como acuerdos de la investigación, con personal directivo y estudiantes se decidió que se reportarían las producciones en protocolos y artículos, y si lo autorizaban, se subirían a internet sus producciones digitales (videos, imágenes, audios, etc.) cuidando de que no aparecieran fotografías personales ni nombres completos.
} 

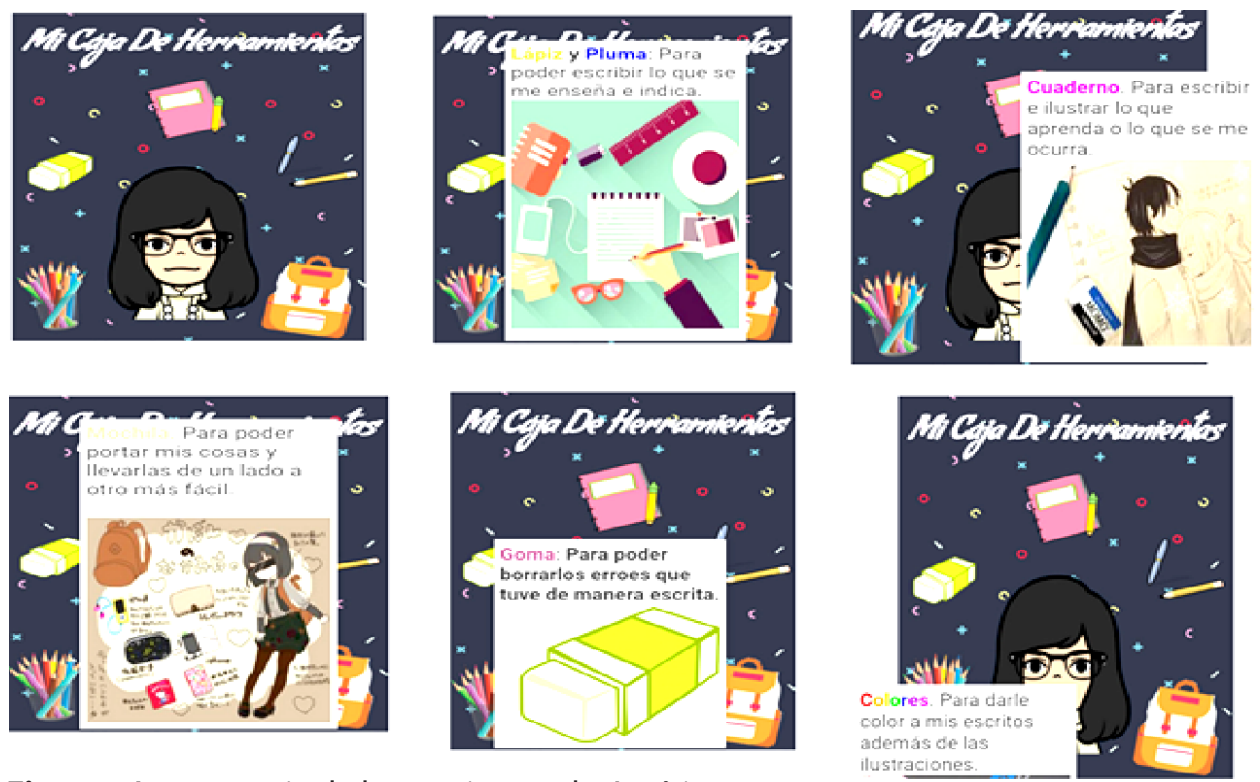

Figra 3: Avatar y caja de herramientas de América. Nota: Imágenes del archivo de la investigación.
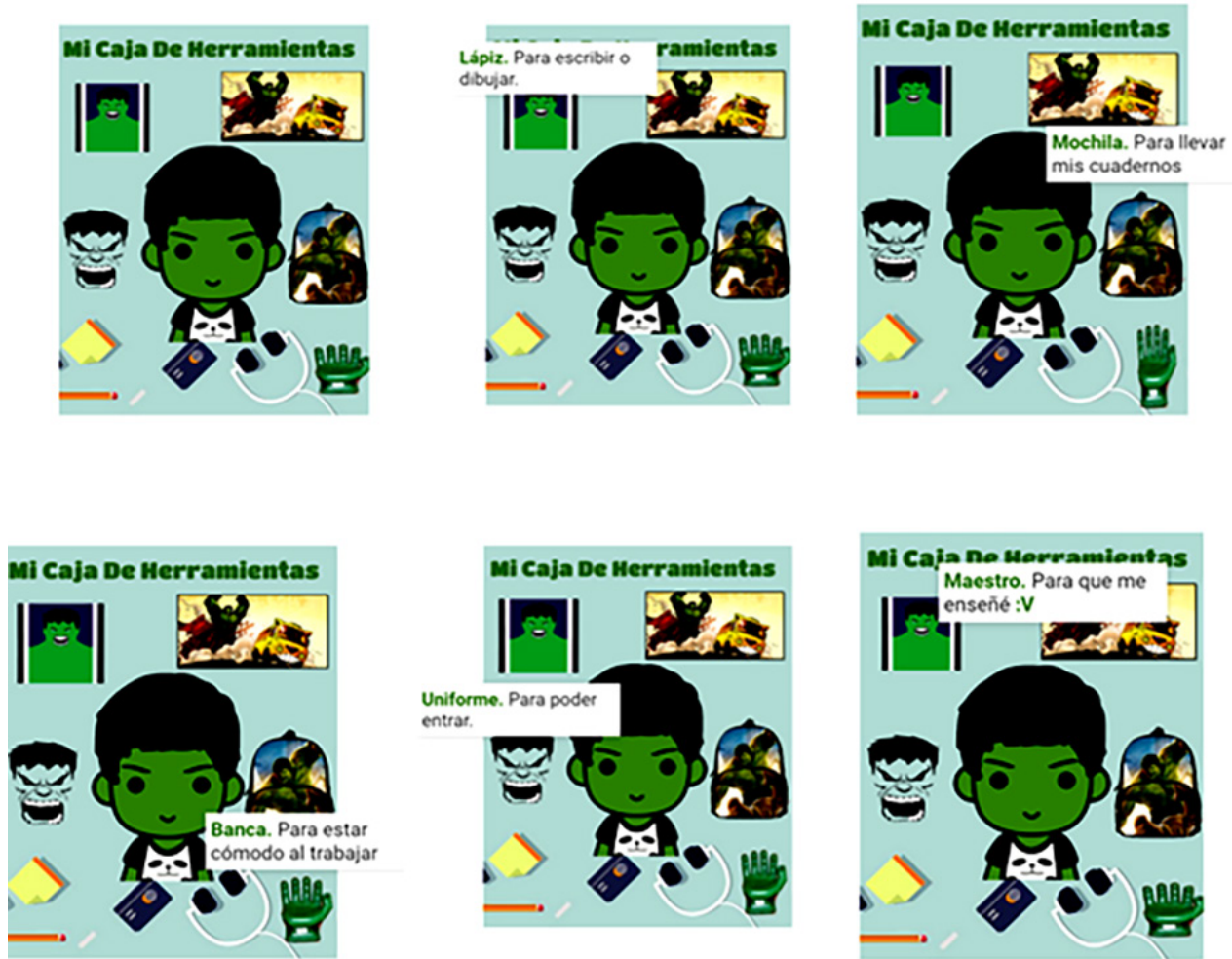

Figura 4: Avatar y caja de herramientas de Eddie. Nota: Imágenes del archivo de la investigación. 
doi: http://doi.org/10.15359/ree.24-1.1

URL: http://www.una.ac.cr/educare

CORREO: educare@una.cr

\section{La voz adolescente}

Algunas acotaciones textuales de nuestro grupo de participantes permiten entender que los alumnos y las alumnas realizan lo que se les pide en la escuela y las actividades o tareas no son elegidas o personalizadas por ellos o ellas o para ellas o ellos: América utiliza lápiz y pluma para escribir lo que se me enseña e indica; Dan y José consideran que los libros son importantes para recabar/conseguir información solicitada por el maestro, pero cuando leen por su cuenta, por gusto o iniciativa propia, es en la red. Para Yael lo relevante es que cada año, al pasar de grado escolar, se les dan los libros que van a usar ese nuevo ciclo. Es de llamar la atención tantas menciones a la mochila donde cargan sus útiles escolares, no solo porque son bastantes y por eso suelen pesar mucho, sino porque es uno de los pocos objetos que pueden elegir a su gusto y personalizar, por lo que suelen portar mochilas con sus personajes o imágenes y colores favoritos; no así su vestimenta y arreglo personal que está condicionado al reglamento del uniforme y que en muchos casos rechazan porque, según dicen, no refleja su identidad.

El tema del uniforme escolar resultó relevante, porque en el plantel existía una controversia al respecto, pues al estudiantado le gustaría ir vestido a mi gusto, con ropa de civil, de calle, normal, llevar tenis de colores y no solo blancos como exige el reglamento del uniforme, porque sirven para lo mismo, hacer deporte. El estudiantado argumentaba que la ropa les permite expresar cómo son, que al personal docente no se le obliga a uniformarse y que el uniforme no hace que se borren las diferencias económicas entre ellos. Únicamente Manuel, consideró que vestir uniforme nos hace sentir iguales con los demás en una connotación positiva.

\section{Fondos de identidad}

Respecto a los fondos de identidad de adolescentes, en la Tabla 1 se enuncian de manera cualitativa aquellos que aparecieron en las producciones elaboradas por ellos y ellas; la clasificación que realizamos coincide en gran medida con lo encontrado por Esteban-Guitart (2012), Poole (2017b) y Subero (2018).

En los avatares aparecieron el tipo de prácticas socioculturales que interesan a este grupo de adolescentes: el dibujo de animé, los videojuegos, los cómics y series de superhéroes, ver y jugar futbol, escuchar música, navegar en la red, conversar con amistades, usar ropa a la moda. En contraste, en el escenario escolar, a partir de lo dicho por el grupo de participantes, privaron las prácticas de realización de actividades convencionales, copia y toma de apuntes, realización de tareas o ejercicios solicitados por el profesor o profesora, búsqueda de información en libros de texto. 
Tabla 1: Fondos de identidad de los participantes

\begin{tabular}{|c|c|}
\hline Tipo de fondos & Menciones de los adolescentes y las adolescentes \\
\hline $\begin{array}{l}\text { Fondos geográficos de identidad. } \\
\text { Territorios más significativos para } \\
\text { aprender }\end{array}$ & $\begin{array}{l}\text { Ciberespacio } \\
\text { Escuela secundaria pública }\end{array}$ \\
\hline $\begin{array}{l}\text { Fondos sociales de identidad } \\
\text { Personas y personajes con quienes se } \\
\text { identifican o les enseñan. }\end{array}$ & $\begin{array}{l}\text { Superhéroes (Hulk, Mazinger Z) } \\
\text { Personajes mediáticos (cantantes y actores juveniles) } \\
\text { Deportistas (Messi, Ronaldo) } \\
\text { Docentes (que les enseñan) }\end{array}$ \\
\hline $\begin{array}{l}\text { Fondos culturales de identidad. } \\
\text { Caja de instrumentos: artefactos } \\
\text { físicos o simbólicos con los que se } \\
\text { autodefinen. }\end{array}$ & $\begin{array}{l}\text { Aprendizajes informales: Teléfono celular, tabletas, laptops, consolas } \\
\text { de videojuegos, audífonos, ropa y atuendo juvenil, insignias y } \\
\text { uniformes deportivos. } \\
\text { Aprendizaje formal: Instrumentos de escritura manual, útiles y } \\
\text { mobiliario escolar, mochila, uniforme, tenis blancos. }\end{array}$ \\
\hline \multirow[t]{2}{*}{$\begin{array}{l}\text { Prácticas de identidad } \\
\text { Actividades más significativas y } \\
\text { frecuentes, que pueden ser o no del } \\
\text { agrado de los participantes. }\end{array}$} & $\begin{array}{l}\text { Relacionadas con aprendizajes informales: Escuchar música, navegar } \\
\text { en internet, visionar contenidos multimediáticos de interés para la } \\
\text { recreación y solución de problemas prácticos, practicar video juegos, } \\
\text { ver el futbol, dibujar personajes de animé, leer cómic, chatear con } \\
\text { amigos, publicar contenidos en sus redes sociales. }\end{array}$ \\
\hline & $\begin{array}{l}\text { Relacionadas con aprendizajes formales: Escuchar la clase de su } \\
\text { docente y tomar apuntes de lo que dice, copiar información del } \\
\text { pizarrón, resolver cuestionarios, hacer tareas y ejercicios en sus } \\
\text { cuadernos, buscar información en sus libros de texto, seguir las } \\
\text { indicaciones que se les dan conforme a la normativa escolar. }\end{array}$ \\
\hline $\begin{array}{l}\text { Fondos institucionales de identidad } \\
\text { Influencias ideológicas que permean en } \\
\text { la identidad que construye el grupo de } \\
\text { participantes }\end{array}$ & $\begin{array}{l}\text { Valores y modelos aspiracionales de la cultura mediática } \\
\text { norteamericana y coreana, así como de personajes célebres del } \\
\text { mundo artístico o deportivo. Aspiración a estilos de vida globales. } \\
\text { No hubo mención a símbolos o personas propios de la cultura } \\
\text { mexicana. }\end{array}$ \\
\hline
\end{tabular}

Nota: Elaboración propia con datos de la investigación.

Es de notar que, aunque nuestro grupo de adolescentes pertenecía al conformado por la autoridad escolar por ser estudiantes problemáticos, en sus autodefiniciones, mediante el avatar y la caja de herramientas, ellos y ellas no se autodefinen de esa manera, ni plasman artefactos o prácticas sociales dañinas o violentas, a excepción de una chica que dice autolesionarse $a$ veces, debido al acoso escolar que recibe. En las plenarias del taller apelaron a que muchas de las actividades escolares son aburridas, repetitivas, poco motivantes y solo en dos casos en su avatar y caja de herramientas, dos varones incluyeron a sus docentes como aquellos agentes "que les enseñan". 
doi: http://doi.org/10.15359/ree.24-1.1

URL: http://www.una.ac.cr/educare

CORREO: educare@una.cr

Las prácticas educativas escolares marginan las prácticas educativas extraescolares que generan el mayor sentido (disposición, motivación, interés, esfuerzo y persistencia por iniciativa propia), según el estudiantado. De acuerdo con lo reportado por el grupo de adolescentes, sus motivos de vida y sus intereses no son tomados en cuenta, no tienen casi ninguna opción de elegir materiales, métodos o actividades a realizar en la escuela, las clases se imparten ante grupos numerosos y todos realizan la misma tarea con pocos apoyos didácticos. De manera notable, dicen que no hay acceso a las TIC, que se les prohíbe usar los teléfonos móviles y que el internet es para la tarea en casa, porque en las aulas regulares no trabajan en la red. El aula de cómputo es insuficiente, los equipos obsoletos y cuando captan señal de red, esta es lenta y no se cuenta con programas ni aplicaciones de diseño o creación de interés para adolescentes, aunado a que el grupo adolescente no lo considera relevante para el aprendizaje de los contenidos curriculares (esta situación fue corroborada por las investigadoras). Las tareas en internet, cuando llegan a solicitarse, se llaman investigaciones, se realizan fuera del horario escolar y consisten en la búsqueda de información factual (definiciones, clasificaciones) sobre temas curriculares que solicitan sus docentes, lo que despierta por lo general poco interés según sus propias palabras.

\section{Discusión y conclusiones}

En este trabajo se han desvelado dos escenarios de vida y aprendizaje desde la perspectiva de adolescentes: el de la institución escolar y el de la cultura mediática y virtual que se han ido apropiando. El acercamiento mediante dibujo identitario y mención de artefactos culturales nos permitió darnos cuenta de la importancia que ambos escenarios tienen, de las contradicciones que se perciben y del sentido que generan respecto a la identidad como persona capaz de aprender.

Dadas las representaciones y explicaciones del grupo de adolescentes de secundaria, podemos decir que su identidad como aprendices en el contexto de la educación formal, en el territorio geográfico escolar, corre en paralelo a su identidad fuera de la escuela, donde se privilegia el aprendizaje informal y autoiniciado, orientado a la convivencia, la recreación y uso del tiempo libre en entornos virtuales, gracias a la mediación de una serie de artefactos tecnológicos, donde el instrumento más relevante en su vida cotidiana es el teléfono celular que les permite el acceso ubicuo a la red. Las herramientas digitales, en sus componentes físico y simbólico, están teniendo un peso importante en los procesos identitarios y en el aprendizaje humano; en el grupo de adolescentes que participó en nuestro estudio, representan la posibilidad de personalizar sus aprendizajes, de reflejar sus identidades, de encontrar una vía de expresión a sus intereses y necesidades. Es decir, el espacio geográfico o territorio donde ocurre el aprendizaje que genera el mayor sentido para el estudiantado adolescente, donde se implica y se siente motivado, es el ciberespacio, donde aprende por su cuenta lo que es de su interés personal y donde fija una trayectoria personalizada, que no puede tener en la escuela. 
Los estudiantes y las estudiantes dicen que navegan y se comunican en la red durante el tiempo libre (recreo, recesos entre clases o a escondidas de docentes y autoridades escolares). Su identidad como aprendiz en la escuela se caracteriza por prácticas educativas mediadas por artefactos culturales de lectoescritura (físicos o analógicos como se les dice ahora), principalmente instrumentos de escritura a mano, cuadernos, hojas de ejercicios y en menor medida, libros de texto. Las principales prácticas en el aula, según reportan, son conducidas por el personal docente: expone en clase, aporta información y explicaciones, realiza evaluaciones de lápiz y papel, hace preguntas o deja tareas para casa. El estudiantado reporta que intentan captar la información más importante que les indica el personal docente o escribe en el pizarrón, y con ello preparan tareas y exámenes. No hacen mención a episodios de personalización de la información en el aula, tampoco metodologías de indagación, aunque el profesorado les pide determinados proyectos en equipo e investigaciones donde buscan información en la red y, ocasionalmente, sienten motivación si logran encontrar algo de su interés.

Son estudiantes a quienes se atribuye en este entorno escolar una identidad de malos estudiantes, reprobados, adolescentes problemáticos, con mala conducta (incluso se les etiquetaba como el grupo de los menores infractores). Manifestaron abiertamente una falta de motivación en las clases, mala relación con una parte de docentes o situaciones donde se consideran víctimas de burlas o acoso. No obstante, al plasmar su identidad en la autodefinición en el avatar correspondiente, se describen como cualquier otro joven de su edad, con gran interés por la música, los videojuegos, la cultura popular mediática norteamericana y coreana, representada por las historias de ficción de superhéroes, los grupos de cantantes juveniles o los jugadores de futbol español y argentino en boga, cuestiones que representaron como símbolos de identidad en sus avatares e infografías. No se veían a sí mismos o a sí mismas como delincuentes ni mucho menos, pero una minoría sí expresaba dudas sobre su capacidad y disposición para el aprendizaje del contenido escolar, lo que atribuía a sus docentes, a la forma en que les enseñan y a las condiciones de la escuela. En cuanto a sus fondos de identidad, es de notar que el profesorado está ausente en las representaciones de nuestro grupo de adolescentes, sus docentes no son los modelos a seguir; la mención de dos chicos a sus maestros, que los consideran importantes en sus representaciones identitarias, es porque les tienen que enseñar.

En esta investigación, al igual que en la de Sola (2015), la generación internet no tiende a autodefinirse mediante categorías de pertenencia estables (etnia, género, nación), sino en términos de sus gustos, deseos, motivaciones y proyecciones (por ejemplo, la música, el deporte, la moda, los personajes de ficción, los animales de compañía, etc.). Asimismo, los personajes mediáticos admirados tienen una conexión con la propia autodefinición. Por otro lado, tal como encontraron Rudduck y Flutter (2007), los jóvenes y las jóvenes que han experimentado fracaso académico y problemas de adaptación a la institución escolar suelen mostrar más criticidad de la enseñanza, de la normativa y de los agentes educativos en comparación al alumnado que 
doi: http://doi.org/10.15359/ree.24-1.1

URL: http://www.una.ac.cr/educare

CORREO: educare@una.cr

no ha tenido dicha vivencia. Para este grupo de adolescentes, el mayor interés e implicación por aprender algo de su interés o que les resultara útil o valioso, se encontraba en escenarios extraescolares, en el ciberespacio, en interacción con la cultura mediática, en escenarios de ocio y entretenimiento ubicuos y virtuales, en la interacción con sus pares.

Mediante los avatares y cajas de herramientas, los adolescentes y las adolescentes lograron plasmar una identidad; se reconocen como personas que son capaces de aprender, que en ciertas condiciones quieren y les gusta aprender, que hay áreas donde son competentes o destacan en sus capacidades como aprendices (por ejemplo, en el dibujo artístico, en la música, en algún deporte), y que pueden tomar iniciativas cuando aprenden. Las áreas donde encuentran sus mayores fortalezas como aprendices no coinciden necesariamente con las demandas de aprendizaje de la institución escolar, y en esta no se suelen reconocer tales capacidades e intereses, por ende, no sienten que se les valore. En este sentido, nuestros resultados son coincidentes con lo planteado por Subero (2018) con poblaciones de adolescentes y jóvenes que también habían experimentado fracaso y rezago escolar, y quienes mostraban importantes discontinuidades entre su experiencia de aprendizaje escolar y de vida cotidiana en función de su contexto, cultura y posición social, como es el caso de nuestro grupo participante.

Por otro lado, este grupo de adolescentes mostró una fuerte implicación en el taller lúdicoreflexivo, donde realizaron las actividades que permitieron explorar sus fondos de identidad mediante la multimetodología autobiográfica extendida (MAE) y, posteriormente, recibieron apoyo para regularizar su situación escolar y aprobar las asignaturas que tenían reprobadas. Esto se debió, a nuestro juicio, a varios factores vinculados, ante todo, con el asunto del sentido del aprendizaje. En primera instancia, les resultó muy interesante y novedosa la exploración del yo (mencionaron que no habían realizado antes este tipo de actividades), así como la compartición de sus producciones identitarias con sus pares del grupo, porque les permitió una mayor comprensión de sí y lograron emplear un discurso no peyorativo ni descalificador de su persona como alguien que aprende. El que se les permitiera hablar del yo y expresar con mucha apertura y sin cortapisas sus pensamientos y emociones, les resultó inédito. Plasmaron ámbitos de su vida en donde se consideran buenos y competentes, en donde se sienten seguros y muestran emociones positivas, pero también pudieron hablar de la ambivalencia de sus experiencias en la escuela o en sus casas. Las actividades que implicaban narrativa de vida, dibujo identitario y uso de aplicaciones en la web, les gustaron mucho y mencionaron que les agradaría que con ese tipo de actividades les dieran otras clases.

Resultó evidente que la identidad digital de este grupo de jóvenes participantes tiene pocas posibilidades de expresión, mejora o educación en la dirección de la ciudadanía digital en el seno de la institución escolar donde estudian, lo que va incluso en contra de las prescripciones del currículo oficial, que se afirma está centrado en el aprendizaje. Ello obedece a que, en esta escuela, como en muchas otras, no hay condiciones o son mínimas para el uso pedagógico de las TIC, el 
equipo de cómputo es insuficiente, obsoleto, no hay buen acceso a la red. Hace falta no solo la mejora de instalaciones y equipo, sino una estrategia de capacitación y empleo de los teléfonos celulares personales con fines educativos. Aunque están prohibidos, como antes dijimos, el alumnado los emplea a escondidas en el plantel, sobre todo para escuchar su música, ver videos o recuperar mensajes, les encuentran poca utilidad para aprender los contenidos escolares, pero tampoco la encuentran sus docentes. Más aún, el alumnado es quien reporta el predominio de métodos didácticos expositivo-receptivos de contenidos que les generan el mínimo interés.

A diferencia de lo encontrado en el estudio de Poole (2017b) con adolescentes de China, no aparecen símbolos que enfaticen la identidad nacional como aspecto relevante al autodefinirse. Un grupo de adolescentes de China colocaban la bandera de su país en su avatar o bien hablaban de rasgos inherentes a su cultura, o de atributos ideológicos vinculados al patriotismo o la religión. En nuestro caso, no aparecieron ni en los avatares ni en la delimitación de los artefactos culturales cuestiones que apelaran a símbolos de la mexicanidad; ni héroes ni personajes que admiran y que plasman en sus representaciones pertenece al país. Tampoco aparecieron en el grupo de estudiantes referencias a prácticas socioculturales relativas a tradiciones mexicanas, ni se mencionaron símbolos religiosos.

Sin embargo, en ambas muestras, china y mexicana, aparecen símbolos donde los adolescentes y las adolescentes se identifican con personajes fantásticos, con superpoderes, animales o seres míticos, así como con deportistas célebres. Es decir, se observa la influencia de la industria mediática y de las tecnologías digitales que transmiten ciertos contenidos globales dirigidos a la población joven. Coincidimos con Sola (2015) en que los personajes con los que se identifican los adolescentes y las adolescentes de la generación internet son aspiracionales, de un nivel económico más elevado, famosos o con capacidades fuera de lo común, es decir, personajes que proyectan identidades deseadas (wishful identification). Sus formas de comunicación y socialización son más amplias que las que se vinculan con personas conocidas y del mismo grupo cultural, pues la virtualidad ha permitido ampliar sus redes y acceder a otros escenarios de vida, a otras culturas e ideologías. Para este autor, la juventud actual tiene una importante interacción con de personajes ficticios y a través de estos, lo que les permite sentir no solo gratificación o promover la proyección de la identidad, sino sentirse en compañía, ser parte de un grupo o comunidad virtual. Las TIC ofrecen un amplio acceso a las generaciones jóvenes al mundo mediático, el cual les despierta el mayor interés, y les acerca a narrativas transmedia, es decir, relatos reales o ficticios de personas y personajes que se transmiten en distintos formatos y medios (internet, series de televisión, música, cine, publicaciones impresas y digitales, sitios web), los cuales tienen un impacto importante en las identidades de las personas. En este caso, y desde la narrativa e iconografía de los chicos y las chicas del estudio, reiteramos la influencia de la cultura mediática coreana y norteamericana, de ciertos iconos juveniles y deportivos, que aparecen como sus modelos a seguir. 
doi: http://doi.org/10.15359/ree.24-1.1

URL: http://www.una.ac.cr/educare

CORREO: educare@una.cr

Finalmente, consideramos que la exploración y fortalecimiento de la identidad del sujeto aprendiz debe realizarse mediante dispositivos pedagógicos que permitan desvelar y fomentar procesos identitarios basados en el reconocimiento y aprecio por la diversidad, inclusión y justicia social que deben privar en la construcción del yo y de los otros sujetos en su papel de actores sociales. Este tipo de dispositivos pedagógicos podría emplearse incluso para discutir críticamente los procesos de aculturación y colonización del pensamiento de los colectivos juveniles, que suelen hacerse invisibles, por ende, tienden a normalizarse.

Tal como proponen diversos estudios de la corriente sociocultural, la cultura escolar se da por supuesta, en cuanto se comparte un marco de referencia, un cierto sentido o disposición por aprender, así como una serie de códigos verbales y no verbales, que favorecen a ciertos colectivos, mientras que en el caso de otros, los más desfavorecidos o rezagados, muestran una distancia que entorpece el vínculo entre dicha cultura escolar con la cotidianidad y los intereses de dichos grupos (Esteban-Guitart, Oller y Vila, 2012). La exploración de la identidad, ajena a toda estigmatización de quien aprende, permite comprender las capacidades e intereses vitales del sujeto de la educación, que pueden ser el punto de partida para repensar las experiencias educativas. En dicha dirección encontramos el valor de los resultados de esta investigación: por un lado, en la mayor comprensión, de parte de estudiantes y docentes, de las identidades juveniles contemporáneas; pero, en el plano de la didáctica, en la posibilidad de proponer experiencias educativas que permitan acercar la cultura escolar a la cultura juvenil y, por ende, a las experiencias e intereses del colectivo de aprendices, en el marco de la cultura a la que se adscriben, sin dejar de lado la posibilidad de reflexionar y cuestionar la realidad en la que se han constituido como sujetos de la educación.

Otra implicación la encontramos en la posibilidad de avanzar en la literacidad digital del estudiantado, no tanto por el manejo en sí mismo de las aplicaciones informáticas puntuales, sino gracias a la posibilidad de utilizar distintos lenguajes de codificación y presentación del conocimiento, así como por la posibilidad de incursionar en la red como creadores y creadoras de contenidos educativos.

El valor de la exploración de la identidad del sujeto aprendiz reside, en resumidas cuentas, tal como plantea Coll (2016), en la posibilidad de avanzar en la personalización del aprendizaje, tomando como punto de partida y de diseño educativo, las necesidades e intereses del estudiantado, para promover su agencia e implicación en el acto educativo.

\section{Referencias}

Amar-Rodríguez, V. (2016). Leer la vida. Una investigación desde la perspectiva narrativa. Revista Latinoamericana de Ciencias Sociales, Niñez y Juventud, 14(2), 975-986. doi: https://doi. org/10.11600/1692715x.14206261015

Bruner, J. (2004). Life as a narrative. Social Research, 71(3), 691-710. 
Bruner, J. (2012). Realidad y mundos posibles. Los actos de la imaginación que dan sentido a la experiencia. Buenos Aires, Argentina: Gedisa.

Bruner, J. (2013). La fábrica de historias (2 ${ }^{\mathrm{a}}$ ed.). Buenos Aires: Fondo de Cultura Económica.

Cassany, D. y Hernández, D. (2012). ¿Internet: 1; Escuela: 0? CPU-e, Revista de Investigación Educativa, 14, 126-141. doi: https://doi.org/10.25009/cpue.v0i14.32

Coll,C.(2013).Laeducación formal en la nuevaecología delaprendizaje:Tendencias, retosyagenda de investigación. En J. L. Rodríguez Illera (Comp.), Aprendizaje y educación en la sociedad digital (pp. 156-170). Barcelona: Universitat de Barcelona. doi: $\underline{10.1344 / 106.000002060}$

Coll, C. (2016). Personalización del aprendizaje escolar. México: Fundación SM.

Díaz Barriga, F. (2005). Principios de diseño instruccional de entornos de aprendizaje apoyados con TIC: Un marco de referencia sociocultural y situado. Tecnología y comunicación educativas, 20(41), 4-16. Recuperado de http://investigacion.ilce.edu.mx/tyce/41/art1.pdf

Díaz Barriga, F., López, E. A. y Vázquez-Negrete, V. I. (2018). Exploración de los fondos de identidad en estudiantes de posgrado a través de una adaptación de la multimetodología autobiográfica extendida (MAE). Papeles de Trabajo sobre Cultura, Educación y Desarrollo Humano, PTCEDH, 14(1), 1-22. Recuperado de http://psicologia.udg.edu/PTCEDH/admin/ publicacions/11.pdf

Díaz Barriga, F., Vázquez-Negrete, V. I. y Díaz-David, A. (2019). Sentido de la experiencia escolar en estudiantes de secundaria en situación de vulnerabilidad. Revista Latinoamericana de Ciencias Sociales, Niñez y Juventud, 17(1), 237-252. doi: https://dx.doi. org/10.11600/1692715x.17114

Dubar, C. (2002). La crisis de las identidades: La interpretación de una mutación. Barcelona: Bellaterra.

Esteban-Guitart, M. (2012). La multi-metodología autobiográfica extendida (MAE). Una estrategia cualitativa para estudiar la identidad, los fondos de conocimiento y las formas de vida. Revista Electrónica de Metodología Aplicada, 17(2), 51-64. Recuperado de https:// dugi-doc.udg.edu/handle/10256/8514?locale-attribute=en

Esteban-Guitart, M., Oller, J. y Vila, I. (2012). Vinculando escuela, familia y comunidad a través de los fondos de conocimiento e identidad. Un estudio de caso con una familia de origen marroquí. Revista de Investigación en Educación, 10(2), 21-34. Recuperado de https:// dialnet.unirioja.es/servlet/articulo?codigo $=4732917$

Esteban-Guitart, M. y Saubich, X. (2013). La práctica educativa desde la perspectiva de los fondos de conocimiento e identidad. Teoría de la Educación, 25(2), 189-211. Recuperado de http:// revistas.usal.es/index.php/1130-3743/issue/view/726 
doi: http://doi.org/10.15359/ree.24-1.1

URL: http://www.una.ac.cr/educare

CORREO: educare@una.cr

García, A. (2008). Identidades y representaciones sociales: La construcción de las minorías. Nómadas, Revista Crítica de Ciencias Sociales y Jurídicas, 18(2), 1-13. Recuperado de http:// www.redalyc.org/articulo.oa?id=18101812

Kossoy, A. (2009). La construcción de la identidad social: Cuestiones metodológicas para su análisis. 27 Congreso de la Asociación Latinoamericana de Sociología. 8 Jornadas de Sociología de la Universidad de Buenos Aires. Asociación Latinoamericana de Sociología, Buenos Aires. Acta Académica. Recuperado de https://www.aacademica.org/000-062/1169

Kozulin, A. (2000). Instrumentos psicológicos. La educación desde una perspectiva sociocultural. Barcelona: Paidós.

Margulis, M. (2001). Juventud: Una aproximación conceptual. En S. Donas (Comp.), Adolescencia y juventud en América Latina (pp. 41-56). San José, de Costa Rica: Libro Universitario Regional.

Peña-Cuanda, M. del C. y Esteban-Guitart, M. (2013). El estudio de las identidades desde un enfoque cualitativo. La multi-metodología autobiográfica extendida y los talleres lúdicoreflexivos. Empiria. Revista de Metodologia de Ciencias Sociales, 26, 175-200. doi: https:// doi.org/10.5944/empiria.26.2013.7157

Poole, A. (2017a). Funds of knowledge 2.0: Towards digital Funds of Identity. Learning, Culture and Social Interaction, 13, 50-59. doi: http://dx.doi.org/10.1016/j.Icsi.2017.02.002

Poole, A. (2017b). "I want to be a furious leopard with magical wings and super power": Developing an ethico-interpretative framework for detecting Chinese students' funds of identity. Cogent Education, 4 1-20. doi: https://doi.org/10.1080/2331186X.2017.1316915

Ramírez, J. D. (2011). La identidad en tiempos de cambio. Una aproximación sociocultural. En C. Monereo y J. I. Pozo (Coords.), La identidad en psicología de la educación. Necesidad, utilidad y límites (pp. 27-44). Madrid: Narcea. doi: 10.13140/2.1.4467.1041

Ricoeur, P. (1995). Tiempo y narración I. Configuración del tiempo en el relato histórico. México: Siglo XXI.

Rudduck, J. y Flutter, J. (2007). Cómo mejorar tu centro escolar dando la voz al alumnado. Madrid: Morata.

Sanjurjo, L. (2009). Razones que fundamentan nuestra mirada acerca de la formación en las prácticas. En L. Sanjurjo (Coord.). Los dispositivos para la formación en las prácticas profesionales (pp.15-44). Mendoza, Argentina: Homo Sapiens Ediciones. Recuperado de https://kupdf.net/download/los-dispositivos-para-la-formacion-en-las-practicasprofesionales-sanjurjo 5af42c5de2b6f5b566e73e87 pdf 
doi: http://doi.org/10.15359/ree.24-1.1

URL: http://www.una.ac.cr/educare

Sinisi, L. (2010).Integración o inclusión escolar: ¿Un cambio de paradigma? Boletín de Antropología y Educación, 1(1), 11-14, diciembre. Recuperado de http://antropologia.institutos.filo.uba. ar/sites/antropologia.institutos.filo.uba.ar/files/bae n01a02.pdf

Sola, S. (2015). La construcción de la identidad narrativa a través de las "historias de vida mediáticas". Un análisis generacional. Revista de Estudios Culturales de la Universidad Jaume 14, 201-220. Recuperado de http://www.e-revistes.uji.es/index.php/clr/article/ view/1794/1523

Stake, R. E. (2005). Investigación con estudio de casos. Madrid: Morata.

Subero, D. (2018). La incorporación de los fondos de conocimiento e identidad en el medio abierto: Los proyectos FICAB y EUCAB (Tesis de doctorado), Universidad de Girona, España. Recuperado de https://www.tesisenred.net/handle/10803/663808\#page $=9$ 